\title{
ORGANIZATIONAL CLIMATE: FROM LITERATURE REVIEW TO AGENDA AHEAD
}

\author{
Syed Sadullah Hussainy ${ }^{1 凹}$ (iD) \\ ${ }^{1}$ Ph.D., Research Scholar, University of Madras, Chennai, Tamil Nadu, India and Lecturer, Faculty of Business, \\ Arab Open University, Sultanate of Oman
}
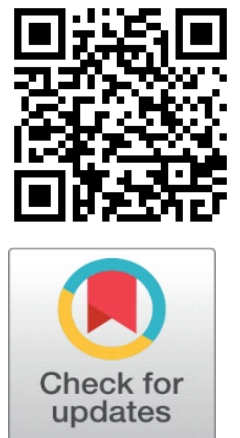

Received 29 November 2021

Accepted 10 December 2021

Published 31 January 2022

\section{CorrespondingAuthor}

Syed Sadullah Hussainy,

syed@aou.edu.om

DOI 10.29121/ijetmr.v9.i1.2022.1107

Funding: This research received no specific grant from any funding agency in the public, commercial, or not-for-profit sectors.

Copyright: (C) 2022 The Author(s). This is an open access article distributed under the terms of the Creative Commons Attribution License, which permits unrestricted use, distribution, and reproduction in any medium, provided the original author and source are credited.

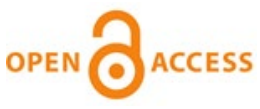

\section{ABSTRACT}

Purpose - Organizational climate affects and influence the employees' performance, motivation, and job satisfaction. The purpose of this research is to synthesize existing literature on organizational climate in order to broaden and clarify the scope of future research on the subject.

Methodology and Approach- For readers to obtain a better understanding of the idea, this study gives a thorough overview of existing empirical and conceptual research on organizational climate, as well as its outcomes and findings published in prominent peer-reviewed Business and Management Journals. The researcher has also explored the four dimension of organizational climate which include peopleoriented climate, rule-oriented climate, result-oriented climate, and innovationoriented climate, as well as the several other dimensions employed by the previous researcher to investigate the subject of organizational climate.

The Result and Findings - The findings of the previous studies were inconsistent, and contradictory. They have failed to recognize the problems with various types of organizational climate and its dimensions. The outcomes are presenting obstacles to organizations' management and highlighting the disadvantage of failing to achieve a positive and healthy organizational climate. The results and findings of this study indicated different rationale on the subject as well as suggestion for a future research plan.

Uniqueness/Value- To create a good organizational climate, this study has proposed a potential research plan which will be not only useful to gain good climate but also maximize the benefits of a positive and healthy organizational climate. This research also adds theoretical ideas and perspectives to the mix, which will aid researchers in better understanding the concept and dimension of organizational climate.

Keywords: Literature Review, Organizational Climate, People, Rule, Goal and Innovation Oriented Organizational Climate, Organizational Climate Dimension

\section{INTRODUCTION}

The modern firms give top priority to evaluate and understand their employees' behavior and activities and this has brought a lot of attention to understand the organizational climate Richard and Kevin. (1998). Aly B Moreno $\mathrm{H}$., mentioned in his LinkedIn post that Organizational Climate is a collective research phenomenon of different types and dimension of climates such as people, rule, goal and innovation-oriented climate. In other words, "Organizational Climate" is also known as corporate climate it has huge impact on employees' productivity, motivation, and performance at work. The concept of organizational climate was introduced in the late 1940 and it has 
become a very essential metaphor for managing and retaining employees in the organization Kumar (2011),Kumar (2011). According to Forehand and Gilmer (1964) the Organizational Climate refers to set of traits that reveal the organization and differentiate it from other organizations and influence the employees' behaviour and a reflect their perception towards the organization. Employees currently, are different from previous one, the skilled employees have numerous opportunities and do not keep long term plan of employment with one organization and rather give importance to continuous self-development, experience, and learning. If they face any minor discomfort and inconvenience with their job in the organization, they make immediate plan to move to other organization (Hussainy. S.S, 2019). They would like to stay with those organizations who provide them with conducive climate which provide autonomy, cohesion, trust, pressure, support, fairness, and recognition Mathew and Selvi (2007). The changing demographic dynamic among the current generation employees in the organizations has encouraged many organizations to re-think and re-design their organizational environmental strategies, system, procedure, and policies Kossivi et al. (2016). The research in Organizational climate is gaining the attention of the academician and scholars, because of the job-hopping mind-set of current generation employees. Besides, the joint-venture and strategic alliances of companies for long-term sustainability in international market has created the necessity to build the vibrant organizational climate which suites the need of global workforce Prange and Mayrhofer (2015).

\subsection{WHY IS GOOD CLIMATE ESSENTIAL IN ORGANIZATION?}

People-oriented culture is essential to create and generate better employees' psychological climate and it fosters a sense of belonging to the organization, dedication, a good psychological contract, and employee retention. Berberoglu (2018) further stated that it might be difficult to improve organizational performance without building a positive organizational climate. Similarly, having a good and positive climate is critical in enhancing productivity, performance, and growth. If the workplace climate is negatively affected, it has a direct impact on employee productivity, motivation, and satisfaction Kundu (2007). As rightly mentioned in the official website of "inscape" a consulting firm, organizations must have people-oriented policies and strategies. Having positive climate is very important for large organizations operating internationally and developed or planning to develop joint-venture and alliances without any boundary conditions in order to achieve high employee performance Madhuka and Sharma (2017). Furthermore, in order to run their operations properly, organizations participating in the global market require a diversified workforce. A people-oriented environment may be used to attract, train, and retain personnel from a variety of backgrounds.

\subsection{ORGANIZATIONAL CLIMATE IS VERY WIDE AND VAST TOPIC}

As stated previously, the organizational climate comprising of many dimensions such as people-oriented climate, rule-oriented climate, goal-oriented climate, and innovation-oriented climate. There are many different factors such as autonomy, cohesion, trust, pressure, support, fairness, recognition etc., play an important role in forming the climate in the organization Arif et al. (2020). Climate 
has always been linked to culture, the environment, and psychological well-being. The impact of several types of organizational climates' variables on business performance has been studied by researchers. However, there are various aspects of organizational climate that have been practiced and experienced in companies but putting them into reality is a huge difficulty. It's difficult to say which aspect of organizational climate is more advantageous to businesses because neither all types of climates apply to all businesses, nor does every aspect of climate have a good impact. Thus, to get the better understanding of individual effect of climates' dimensions, researcher conducted an extensive literature review by categorizing the climates dimension into four categories. Before continuing to this review paper, researcher gone through the review paper written by the following authors. They are James and Jones (1974). Organizational climate: A review of theory and research, Schneider (1985). Organizational behaviour. Annual Review of Psychology, Monika, M. Yukthamarani et al. (2013), Organizational Climate on Employees' Work Passion: A Review, Schneider et al. (2012) Organizational climate and culture. Annual Review Psychology, DUAN et al. (2014) Organizational Climate: A Review of Conceptualization, Theory and Prospects, Kaliyamurthy, K. (2016) A Detail Review of Organizational Climate), Omole et al. (2017), Organizational Climate Review, McWinner (2019), Organizational Climate and Job Satisfaction: A literature review, Khan et al. (2020). Organizational Climate: Review, Powell et al. (2021), Measures of organizational culture, organizational climate, and implementation climate in behavioural health: A systematic review. Implementation Research and Practice.

It has been found that no author focused on systematic review of literature specially four dimensions of climates. The literature was systematically separated in this study using the main broad headings such as Definition and concept of organizational climate, Climate dimension, Attribute contributing to the formation of organizational climate, and the most commonly used method of climate measurement considered, among others. Finally, the study explored the causes for the contradictions in the results and offered a future research agenda to address them.

\section{THE METHODOLOGY USED TO ORGANIZE THE LITERATURE}

A review of the literature was conducted to analyse and evaluate various aspects of organizational climate and the factors affecting organizational climate. This paper also presented the results published in peer-reviewed publications. The top leading journals in the fields of human resources management and organizational behaviour were chosen for this study. The names of some of these leading journals are International Journal of innovative research and technology, International Journal of creative research thoughts, and Annual Review of Psychology etc. The UGC (University Grant Commission) in India awarded the selected journals an $\mathrm{A}^{*}$ rating. The remaining publications were omitted since they did not contribute studies in the topic of organizational climate. The following key words were used in the topic, abstract, and keywords of the studies from 1960 to 2020. The organization climate, types of organizational climate, dimension of organizational climate, people-oriented climate, goal-oriented climate, rule and innovation-oriented climate, attribute of people-oriented organizational climate, organizational climate in contemporary organizations. In addition, the citations in the retrieved studies were examined, and some additional studies were included for this study. The year 1960 was chosen as the starting point for this study since the organizational climate began in 1960. Because the researcher believes that this will 
help to explain the conflicting results of each component of organizational climate, a large number of papers were picked from various UGC care list journals for this research.

\section{DEFINITIONS AND IMPORTANCE OF ORGANIZATIONAL CLIMATE IN THEORETICAL POINT OF VIEW}

In terms of definition and dimension, many authors have expressed differing views on organizational climate. Organizational climate has been characterized by some authors as the interaction of employees with the organization's current environment Burke et al. (1992). Others have characterized organizational climate as a snapshot of an organization in terms of employees' perceptions, claiming that organizational climate is more dynamic than culture since individual perceptions can change when events and circumstances in the organization occur Obeng et al. (2021). It also refers to the members' perceptions and impressions of the organization and its internal environment, which they interact with on a regular basis Zacher and Jie (2016). After examining various researchers' perspectives on organizational climate, the researcher argues that organizational climate refers to employees' perception of relevant aspects of organizational working environment and routine practices prevailing in the organization. To put it another way, it is fully made up of employees' perceptions about the organization's environment as a result of their work experience.

There has been a lot of conflict in the organizational climate dimension since many researchers have examined a specific dimension in which they are interested rather than trying to build a single view of the dimension, which will surely be a difficulty for future researchers Balachandran and Immanuel. (2007). Studying and evaluating organizational climate is complicated, according to the study, because organizations vary greatly in terms of size, complexity, structure, products, vision, mission, and so on. Research studies in the topic of organizational climate have been beneficial, and additional research are needed to address or minimize differences of opinion on organizational climate issues. Researcher also believes that there is a need of identifying some dimensions that are common and can be applied to all organization and considering such need the researcher here proposed the following dimension of climate with their definitions and meaning.

\section{REVIEW ON ORGANIZATIONAL CLIMATE}

This study contains systematic literature review to examine different dimension of the organizational climate and their findings. Many researchers have recommended their own types of variables for examining and classifying the organizational climate and its attributes. For example, Sargunam and Rathnamala (2014) studied the Organizational Climate and its impact in Anna University and identified the relationship between Organizational climate and job satisfaction. Afshin et al. (2020) evaluated English teachers' job satisfaction: Assessing contributions of the iranian school organizational climate in a mixed methods study. Ghavifekr, Simin; Pillai, Nova Sheila studies investigated relationship between organizational climate and school performance and job satisfaction. Sharma (1969) study was replicating Halpin and Crofts study on a random sample of Rajasthan Schools in India and investigated relationship between organizational climate and teachers' satisfaction, schools' effectiveness, and leadership behaviour. As mentioned in the book of School Management which as published by S B Nanja, 
Franklin (1975) study was focused on identifying types of climates of colleges of education in Gujrat, India and investigated the relationship between Organizational climate and morale of college professors. Jan and Khan (2015) studied and compared morale of Teachers Working in Various Higher Secondary Schools of Kashmir Division- it was a comparative Study of Science and Arts Teachers. Berberoglu (2018) stated that good organizational climate helps the organizations in achieving higher level of commitment, which is essential to develop positive employees' attitude. His study was on health care professionals and the result of the study revealed that the organizational climate is having high positive co-relation with the organizational commitment and employees' attitude. Sambandam and Chockalingam (2019), Yee and Mahadevan (2017) evaluated the effect of the organizational climate on employees' performance in manufacturing industry and Malaysian consultancy firm and the results of these studies indicate that the various factors of organizational climate influence positively on performance of employees and motivate them to perform better in both contexts. Chneider et al. (2011) summarizes and expanded the work done by Benjamin Schneider, Mark G. Ehrhart, and William H. Macey (2011) in which they provide the ideas and review of the history of organizational climate. Zaher and Yang (2016) did research on successful gain at work and they introduced the concept of organizational climate for successful age and examine it as a buffer of the negative relationship between the age of employees and opportunities, i.e., belief about future goals and possibilities at work. They applied multilevel analysis and overall finding suggest that Organizational climate is an important resource for successful aging at work. Suwastawa and Sudibya (2019) studied the influence of organizational climate and compensation for employee job satisfaction and turnover intention at Kapla New Kuta Beach. The result of this study shows that there is a positive and significant relationship between organizational climate on job satisfaction but in this study organizational climate has negative effect on intention to leave the organization. To support these variables and their contradicting results in Organizational climate research, many researchers have acknowledged various theoretical perspective such Social Climate of Lewin, Lippitt \& White as stated by Srivastav (2009). Lewin and others mentioned that shared beliefs and values of organizational member comprise of perceived work environment. Schneider (1975) suggested that the idea of Organizational climate depends on certain assumption which are related to Gestalt School of psychology and the school of functionalism. Glick (1985) mentioned that climate add value to organizational and individual behaviour.

Gestalt psychology, Functionalism, the person-environment fit model, and Lewinian Field theory are four theories that can be utilized to understand organizational climate. Gestalt Psychology is based on two assumptions: first, that people try to understand their surroundings, and second, that people try to establish order in their surroundings in order to successfully adapt their behaviour to the workplace. In his article, Schneider (1975) attempted to interpret Gestalt's assumptions as "meaningful apprehension of order for the perceiver based on the equivalent of Psychological signals." Individual behaviour, according to this theory, is influenced by the environment. Gestalt defines functionalism as "the transmission of order into behaviour," in which individuals express their conduct based on the order they generate. This will also help them to adapt effectively, seek knowledge, and respond appropriately Schneider and Snyder (1975). Kurt Lewin (1935) proposed that the person-environment interaction is the key to understanding people's cognitive, affective, and behavioural reactions. It is described as the degree to which person and environmental qualities are compatible (French, Caplan, and Harrison (1982); Rounds et al. (1992), Kristof- Brown et al. (2005). In 1951, this theory was expanded to include individual behaviour, and it was dubbed Lewinian 
Field Theory. Gestalt psychology's second assumption stated that people connect the order they construct with the environment they are in, which then changes into behaviour. Lewinian Field theory is another assumption of Gestalt psychology. In his work "Field theory in Social Change," Lewin conceptualized the link between individuals and their social environments based on this principle. He went on to say that behaviour is the result of a person's interaction with their surroundings. As a result, these theories lay the groundwork for further research into the factors that influence the establishment of organizational climate. These underlying theories provide a conceptual explanation and logical reason for the study's classification of many types of organizational climates, with diverse theories supporting the findings. As a result, a thorough investigation was carried out to uncover several aspects of organizational climate and their impact.

\section{OTHER DIMENSION STUDIED BY PREVIOUS RESEARCHERS}

In the last few decades, the concept and meaning of organizational climate have shifted. The researchers' parameters for measuring the organizational climate have also been altered. The researcher has attempted to identify the dimension of organizational climate that has been examined by some of the earlier researchers, which are discussed below.

Likert (1967) investigated the organizational climate and measured it using six dimensions: leadership, motivation, communication, decision-making, and goal setting. In their research work "Perceived Organizational Climate and Process of Sales-person Motivation," Campbell et al. (1970) emphasize four dimensions of organizational climate: Task, Structure, People, and Technology. Schneider and Bowen (1985) conducted research on employee and customer perceptions in the service industry (banks). In this study, he proposed five dimensions to explain the organizational climate: work facilitation, supervision, organizational career, organizational status, and socialization. Koys and DeCotiis (1991) emphasis on seven important dimension of organizational climate such as Autonomy, Cohesion, Trust, Stress at work, Fairness, support, and recognition and claim that these dimensions will also support organization in developing positive psychological climate. Fey et al. (2001), in their research paper "Organizational Climate Similarity and Performance: International Joint Ventures in Russia" examines how organizational climate dissimilarity between parent companies and the joint venture organization affect joint venture performance they used control commitment and national culture as variables of their studies. Rožman and Štrukelj (2021) have used five dimensions of organizational climate in their research to understand its effect on their work engagement of the employees. They are Leadership, Employees' relation, Employees' commitment, Employees' satisfaction, and employees' motivation.

\section{TYPES AND DIMENSION OF ORGANIZATIONAL CLIMATE}

The researcher used four broad dimensions to describe the dimension of organizational climate in this study and elaborated them in detail with extensive literature review. 


\subsection{PEOPLE-ORIENTED CLIMATE}

People-oriented climate should be developed in organizations, with the primary goal of appreciating and respecting people Skvarciany et al. (2015). People climate will create a sense of fair treatment among employees as a result of the mutual respect. To develop this superior subordinate connection is critical and helps to develop feeling among employees that they are a vital "cog" in the organization's wheel, and to offer profit sharing and other incentive options to make them feel like they are an important part of the team. Employees should be rewarded at the workplace for their contributions, which are essential to the growth of innovative ideas. Likewise, establishing a work-life balance culture will help to create a positive atmosphere at the workplace. Today's employees prefer a work schedule that is flexible. In order to build a people-oriented organizational atmosphere, it is also necessary to invest in employees' growth and success. The truth is that the success of employees and the success of the company are inextricably linked. This can be accomplished by recognizing the requirements of employees and providing appropriate support, which will not only motivate them but also give them a sense of empowerment in the company.

Koys and DeCotiis (1991) identified various factor which contribute psychological climate in organization. The psychological climate is mainly based on employees' perception about the work and the organizations which has been developed based on their experience about the organization. They include the following: Autonomy refers to the degree to which employees are able to organize their work, as well as their roles and obligations. Cohesion can be defined as peer relationships, collaboration, friendliness and affection, sociability, lack of conflict, and status distinctions. Managers' sensitivity and faith in leaders, as well as transparency and warmth rather than aloofness, are all examples of trust. PressureThis is defined as the job's overall stress caused by the role, workload, uncertainty in the role, and conflict. Support- This refers to the general assistance that employees receive from their bosses. Recognition refers to praise and criticism, as well as opportunities for growth and promotion, as well as prizes and punishments. Fairness- This refers to the fairness of the reward system, the clarity of promotion, and the clarity of policies, among other things. The people-oriented climate in the organization will help the organization to achieve positive psychological climate.

\subsection{RULE-ORIENTED ORGANIZATIONAL CLIMATE}

The company places a strong emphasis on rules and regulations in the ruleoriented climate. It is based on the organization's defined rules, regulations, and processes Rudd and Mills (2020). People will not be permitted to perform anything unless clear guidelines have been established. This attempts to ensure that all members of the organization are safe. To put it another way, the rule-oriented climate of an organization is based on tradition and a robust set of norms that cannot be readily modified, and employees are expected to follow procedures and follow rules and regulations. In a rule-oriented environment, pre-determined scenarios are frequently planned to use established processes and procedures. McDonald's is the best example of an organizational climate based on rules. Everything from how to cook and fry French fries to how to make burgers, ice cream, and tea has been meticulously documented. This strategy works well in organizations with a lot of structure and a clearly defined hierarchy, where everyone understands exactly what their responsibilities are. When a customer registers a complaint, for example, the 
process begins with an assistant manager and progresses to a manager, district manager, and so on. People will be motivated to obey the unchangeable norms, traditions, and values, and they will be well aware of the consequences of not adhering to the laws and regulations. The emphasis given to establish rule because of the assumption that, they control behaviour and bring structure, uniformity, and consistency to company. The policies and procedures are part of company's rule and represent the rules. Some researchers believe that, if rules are practiced excessively in the company, it will impede the organizational performance Drexler (1977).

\subsection{GOAL-ORIENTED ORGANIZATIONAL CLIMATE}

Goals are critical to an organization's success because they lead employees toward tasks and objectives. The term "goal-oriented climate" refers to the behaviours of organizations that are primarily focused on attaining the organization's objectives. The organization should create an environment that consistently motivates personnel to achieve the intended result Pavle et al. (2016). Organizational goals might be long, medium, or short term. Long-term objectives are strategic in nature and can be divided into medium-term and short-term objectives. The goals of the organization should be well-aligned, and they should aid in the integration of interconnected organizational resources as a means of achieving organizational objectives. The figure below depicts how several forms of organizational goals are intertwined, often known as the pyramid of purpose.

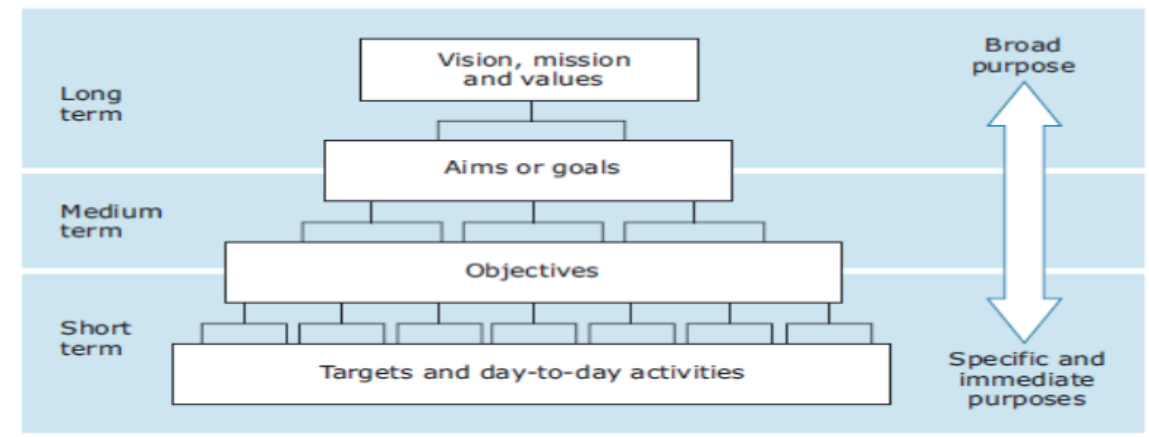

Figure 1 The Pyramid of Purpose

Source Understanding marketing and financial information, Business school, Open University, UK. Produced for the course team by Andrew Lind ridge and Haider Ali and Graham Francis and Michael Lucas

Senior managers must consider and plan for long-term objectives while pursuing a broad strategic mission. The timeframe for front-line managers becomes shorter, and the goals become more detailed. The frontline managers must meet their respective goals in a short period of time. As a result, the purpose pyramid is frequently referred to as the "cascade of objectives." For example, while an organization may have long-term goals, line managers' targets may serve as a daily indicator of what they should be doing to fulfil their role in contributing to the attainment of the overall goals. There's a fair possibility that whichever type of organization you work for has at least one barrier that stops it from easily achieving its objectives. In a business, it might be the company's limited number of customers, which competitors are also striving for. It could be the tiny number of people who can be persuaded to donate money to a good cause. The government may impose 
cash limits in the public sector. Due to the ongoing scarcity of funds, priorities must be identified, and sufficient funds supplied to them. The goals should be SMART (Specific, Measurable, Achievable, Realistic and Timed). Having clarity of goal is very essential and managers should try to involve everyone in the organizations' goals setting and goals planning because when people participate in the goal setting, they will be having clarity about their targets and goals that they have to achieve.

\subsection{INNOVATION- ORIENTED ORGANIZATIONAL CLIMATE}

It is vital for organizations to be able to adapt and survive in today's dynamic and changing environment, which needs the development of innovation capacity Annika et al. (2019). The phrase "innovation" relates to the creation of new ideas, which is frequently a hazy and uncertain process Daft (1978), Amabile 1988; Daman pour and Evan 1984). The attempt to create something new is frequently the source of innovation (Anderson, Potonik, and Zhou, 2014). Organizations should develop an entrepreneurial mindset to foster an environment of innovation and creativity. Three components of the innovation climate include risk-taking, proactiveness, and inventiveness Covin and Lumpkin (2011), Lumpkin and Dess (1996), Miller (1983). Other features of creative and innovative businesses have been found by Yström et al. (2015) are challenge, freedom, concept, support, trust, debate, and risk taking. Organizations that are known for being forward-thinking in terms of products, services, procedures, policies, and other factors should have a different environment than those that are deliberately conservative or out of date Ekvall (1996). A highly creative atmosphere has been linked to increased market share, sales volume, and the ability to implement complex work designs, among other things Isaksen and Ekvall (2010) found that "the organizational environmental characteristics play a critical influence in stimulating the workforce to think creatively and augment organizational performance by having radical product innovations" in a study of idea generation among middle management.

\section{MEASURING THE OUTCOME OF ORGANIZATIONAL CLIMATE}

As previously stated, researchers have evaluated the organizational climate using several dimensions and contributing factors. This research also focused on examining the relationship between previous research findings on organizational climate and performance outcomes, which had ambiguous results with evidence of positive, negative, and non-significant effects on organizational performance in general and employee performance in particular. The findings of this study could be due to a variety of factors. With the support of organizational climate literature, previous researchers have analysed the contradicting findings. Based on the literature, several scholars have offered several ways to examine and evaluate the organization's climate. According to Koys and DeCotiis (1991), some of the primary elements that may influence organizational climate include autonomy, cohesion, trust, and liberty. Other authors have brought up concerns like conflict and the perception of racism in the workplace as examples of a terrible working environment. Furthermore, some researchers have examined the organizational climate from many perspectives, claiming that the climate may be understood in four dimensions: people, rule, results/goals, and innovation. Skvarciany et al. (2015) have particularly emphasized on the necessity of recognizing and valuing employees in the organization. Skvarciany, Viktorija \& Iljins, Juris \& Gaile-Sarkane, Elina's work is clearly related to the Koys and Decotiis since they place a strong emphasis on individuals, according to the researcher's personal observations. Many 
experts, according to talentculture.com, have explored the detrimental effects of carefully following numerous rules, regulations, and procedures. Researchers such as Rudd. D and Mills J.R researched and analysed the rules, regulations, and processes in the business.

As a result, future research can focus on the impact of rules on the organizational climate in general, as well as employee perception in particular. Pavle KOMENI, Vanda BAZDAN, Besim AGUAJ, Grahme Francis, and Michael Lucie's emphasized the necessity of establishing a goal-oriented climate in the company in their research. The goal-oriented organization is one in which members achieve their principal objectives. The majority of corporate climates are goal-oriented in some form, which influences managerial style. Andrew Lind ridge, Haider Ali, Graham Francis, and Michael Lucas (The Open University, UK) course team have elaborated on the pyramid of purpose, with the goal of describing how multiple organizational goals should be linked to which he has given the name "cascade of objective." For example, some researchers compared and measured each dimension of organizational climate independently, while others compared and measured each dimension of organizational climate jointly. As a result of the varied operationalization of climate variables, different results may be obtained. Hunter, Bedell, and Mumford investigated the numerous approaches to building innovative and creative businesses. He focused on challenge, freedom, idea, support, trust, debate, and risk taking etc. are some of the common measures to understand the innovation climate of the organization.

Several other research studies have evaluated the various types of date and concluded the result. Some of the studies in which researchers. Suwastawa and Sudibya (2019) have used longitudinal data and other studies have used cross sectional data Obeng (n.d.) . Although some studies, particularly longitudinal and cross-sectional studies, cannot show a causal relationship, causal interpretation is used to determine the cause-and-effect relationship. At various levels of the company, the performance results of the organizational climate have been measured in a variety of methods. For example, senior management can benefit from a positive climate by getting things done by employees and making organizational policies and strategies easier to implement. As a result, different studies have used different variables at different levels, resulting in results that are contradictory.

In the literature review Berberoglu (2018) reported that contextual variable work as intervening variables which can affect the organizational climate. In another study Skvarciany et al. (2015) mentioned that difference in contextual variables may lead to different results. Besides that, several researchers have hypothesized different type of relationship between organizational climate and organizational performance and some researchers has examined the linear relationship Yee and Mahadevan (2017) and some have measured non-linear relationship Kumar (2011).

\section{FINAL SYNTHESIS AND FUTURE RESEARCH AGENDA}

This section focuses on numerous future research opportunities in organizational climate, which have a lot of potential for resolving conflicting results and reducing the harmful effects of poor climate in organizations. As a result, the list below provides research options, as well as numerous fresh chances and opportunities for future research in the organizational climate. 


\subsection{AGENDA OF RESEARCH 1: CROSS-COUNTRY AND CROSS- INDUSTRY STUDY}

One of the most popular and developing subjects for future research is organizational climate. Organizational climate research is primarily conducted in advanced and established countries such as the United States, Canada, Germany, and the United Kingdom, with only a few studies recorded in developing countries, particularly those in the Middle East. Most modern organizations operate in multiple locations and have the identity of MNCs, so it is critical for them to achieve good climate in all of their branches, because if the climate in one of their branches is affected, it will have a negative impact on the entire organization across all branches.

Furthermore, primary data was acquired from enterprises operating in developed countries for empirical studies, and the conclusions may not apply to other countries. This represents previous study on organizational climate in the context of globalization, however the expansion of emerging markets, particularly in the Middle East, implies that research in advanced and developed countries will not last long. Furthermore, main data was acquired from companies operating in developed countries in earlier studies; so, such results cannot be applied to other countries in general and specially in the middle eastern countries. More research on organizational environment in diverse industries and nations is needed and it is one of the main proposals of this study.

\subsection{AGENDA OF RESEARCH 2: COMBINING THEORIES RELATED TO ORGANIZATIONAL CLIMATE}

From review of literature, it has been found that many previous scholars have investigated many ideas on organizational climate, with Gestalt psychology, Functionalism, Person-Environment Fit Model, and Lewinian Field Theory being among the most famous. Some of these theories are supported by Shreedevi and Bharamanaikar (2017). Schneider, for example, described organizational climate in his research article "Organizational Climate: An Essay, (1975)," and interpreted the Gestalt opinion as "meaningful Apprehension of order based on the equivalent of psychological cues." As a result of this research, researchers may analyse the relationship between organizational climate and organizational performance in the future by combining diverse organizational climate ideas that can be useful in managing and developing positive climate.

\subsection{AGENDA OF RESEARCH 3: EXPLORING THE UNEXPLORED OUTCOMES}

From the literature available, some outcomes such as organizational performance in general, departmental, or sectional performance in particular, top management performance, employee's performance, productivity, retention, and psychological contract etc. have received less attention. Some other researchers have studied the relationship between organizational climate and outcomes such as employee turnover, retention, commitment, and communication Kristof- Brown et al. (2005). There is a lack of a link between organizational climate and employee motivation has been documented by a small amount of study. As a result of this research, future researchers should look at the relationship between organizational 
climate and commitment, retention, motivation, satisfaction, and retention, among other things, particularly in the context of Middle Eastern organizational environment.

\subsection{AGENDA OF RESEARCH 4: EXPLORING THE UNEXPLORED DIMENSION}

Pavle et al. (2016) divided the organizational climate dimension into four categories: people-oriented climate, rule-oriented climate, result-oriented climate, and innovation-oriented climate. However, no previous study examined each dimension and its impact on individual and organizational performance and other aspect of the organization especially in the Middle eastern context. Future research could investigate the impact of many aspects of organizational climate on organizational and employee performance, as this study suggests. Most of the previous research on organizational climate has been conducted in nations outside of the Middle East region and has used multiple dimensions. Moreover, very few recent studies have emphasized on exploring the unexplored dimension of organizational climate such teamwork, relationship at work, employees' empowerment etc. Therefore, future researchers can decide the effects those variables mentioned in 8.3 (Agenda of Research 3: Exploring the unexplored outcome) along with other rarely examined variable such as relationship or impact of teamwork, relationship at work, employees' empowerment, employees' engagement, performance, and productivity etc., on organizational climate. Furthermore, this study also suggests the future researcher can also think of doing the comparative studies.

\subsection{AGENDA OF RESEARCH 5: EXPLORING THE COMBINED EFFECT OF MULTIPLE DIMENSION}

Most organizational climate researchers agreed that one of their studies' weaknesses is that they have looked at a few aspects of the organizational climate and did not pay attention to others. Previous researchers didn't focus on the combined influence of dimensions of organizational climate. As a result, this study propose that the future researchers should investigate the combined effect of multiple variables of organizational climate on organizational performance and individual performance.

\subsection{AGENDA OF RESEARCH 6: OPERATIONALIZATION OF CLIMATE VARIABLE}

Previous studies have focused into several organizational climate measurement methods and metrics using a variety of methodologies and measures. As indicated by Pavle et al. (2016) future studies can use other statistical techniques and tools to evaluate the difference by operationalizing the organizational climate in terms of people, rule, goal, and innovation, along with other factors contributing to the organizational climate. 


\subsection{AGENDA OF RESEARCH 7: ROLE OF ORGANIZATIONAL LEADERS IN DEVELOPING CONDUCIVE ORGANIZATIONAL CLIMATE}

Only a few studies have looked at the importance and role of leadership and top management in creating a favourable organizational climate, while others have looked into the other aspects of leadership and their relationship to organizational climate. The use of climate measurement approaches such as people, goal, rule, and innovation, among others, necessitates the active participation of organizations top management in developing positive climate. The empirical data shows that the organizational climate has a considerable impact on employee motivation, satisfaction, and turnover. Finally, this study proposes that future research should focus on the importance leadership in developing a healthy organizational climate as well as the developing the factors which contribute to the development of a positive psychological climate.

\section{IMPLICATION}

Despite the fact that much research has been done on the topic of organizational climate over the last several decades, several essential aspects of organizational climate and several essential have been focused overlooked. As a result, this research places main focuses on the operationalization of organizational climate and its factors, as well as the causes for inconsistencies and a research agenda for the future. This research has aided in a variety of ways. For starters, future research can choose from a variety of proposed research agendas on organizational climate. Second, practitioners can devote more time to cultivating a positive organizational climate through justice, liberty, cohesion, and open communication, among other factors that contribute to the development of a favorable psychological climate among employees. Finally, the study's practical significance stimulates organizational managers to support variables that contribute to the development and formation of a healthy organizational climate in the organizational setting for benefit of organizations and their employees.

\section{CONCLUSION}

This research work is unique in that it conducts a comprehensive review of the literature on organizational climate. This research paves the way for more research in the future. In conclusion, our literature review covers the meaning and concept of organizational climate, its dimensions, factors that influence organizational climate, the operationalization of organizational climate variables, and the impact of organizational climate on individual and organizational performance. Furthermore, this research reveals various reasons for inconsistencies in organizational climate research results and also elaborated on the importance of future research. This type of literature review contributes to the growth of existing knowledge on the topic of "climate" while also identifying research opportunities for future studies. We believe that this literature analysis will aid future researchers in gaining a comprehensive picture of the current status of existing research as well as future scope and potential in the topic of "Climate", and our recommendations will promote greater research in this area. 


\section{REFERENCES}

Adwiz (2021,31 November). Inspire Higher Levels Of Performance \& Engagement. Retrieved from https://www.inscapeconsulting.com/

Afshin Rezaee, Hooshang Khoshsima, Esmail Zare-Behtash \& Abdollah Sarani | Xiaofei Lu (Reviewing editor:) (2020) English teachers' job satisfaction : Assessing contributions of the iranian school organizational climate in a mixed methods study, Cogent Education, 7 :1, DOI : 10.1080/2331186X.2019.1613007 Retrieved from https://doi.org/10.1080/2331186X.2019.1613007

Andrew Lindridge and Haider Ali and Graham Francis and Michael Lucas (2011) Understanding marketing and financial information, The Open University, Walton Hall, Milton Keynes, MK7 6AA Copyright (C) 2011 The Open University, ISBN 978184873653 5, 3.1

Annika Olsson, Karla Marie B. Paredes, Ulf Johansson, Malin Olander Roese \& Sofia Ritzén (2019) Organizational climate for innovation and creativity - a study in Swedish retail organizations, The International Review of Retail, Distribution and Consumer Research, 29 :3, 243-261, DOI : 10.1080/09593969.2019.1598470 Retrieved from https://doi.org/10.1080/09593969.2019.1598470

Arif Prastiawan and Imam Gunawan and Arda Purnama Putra and Dimas Arif Dewantoro and Puri Selfi Cholifah and Ni Luh Sakinah Nuraini and Titis Angga Rini and Rizqi Fajar Pradipta and Kukuh Miroso Raharjo and Dedi Prestiadi and Ence Surahman, (2020) Proceedings of the 1st International Conference on Information Technology and Education (ICITE 2020),725728, Issn. 2352-5398, Isbn.978-94-6239-299-1, Retrieved from https://doi.org/10.2991/assehr.k.201214.327; https://doi.org/10.2991/as sehr.k.201214.327

Arvey, Richard \& Murphy, Kevin. (1998). Performance Evaluation in Work Settings. Annual review of psychology. 49. 141-68. 10.1146/annurev.psych.49.1.141. Retrieved from https://doi.org/10.1146/annurev.psych.49.1.141

Balachandran, M \& Thomas, Immanuel. (2007). Dimensions of Organizational Climate. The Psychespace. 1. 27-36 Retrieved from https://www.researchgate.net/profile/Immanuel-

Thomas/publication/272793409_Dimensions_of_Organisational_Climate/1 inks/54eed8340cf2e2830865b842/Dimensions-of-OrganisationalClimate.pdf

Berberoglu, A. (2018) Impact of organizational climate on organizational commitment and perceived organizational performance : empirical evidence from public hospitals. BMC Health Serv Res 18, 399. Retrieved from https://doi.org/10.1186/s12913-018-3149-z

Berberoglu, A. (2018) ; Impact of organizational climate on organizational commitment and perceived organizational performance : empirical evidence from public hospitals. BMC Health Serv Res, 399. Retrieved from https://doi.org/10.1186/s12913-018-3149-z

Burke, M., Borucki, C., \& Hurley, A. (1992). Reconceptualizing psychological climate in a retain service environment : A multiple stakeholder perspective. Journal 
Organizational Climate: From Literature Review to Agenda Ahead

$\begin{array}{llcclc}\text { of Applied Psychology, 77, 717-729. } & \text { Retrieved } & \text { from } \\ \text { https://doi.org/10.1037/0021-9010.77.5.717 } & & \end{array}$

Campbell, J. J., Dunnette, M. D., Lawler, E. E., \& Weick, K. E. (1970). Managerial behavior, performance, and effectiveness. McGraw-Hill

Chneider, Benjamin \& Ehrhart, Mark \& Macey, William. (2011). Organizational climate research : Achievements and the road ahead. 10.4135/9781483307961.n3.

Covin JG and Lumpkin GT (2011) Entrepreneurial orientation theory and research: Reflections on a needed construct. Entrepreneurship : Theory \& Practice 35(5) : 855-87. Retrieved from https://doi.org/10.1111/j.15406520.2011.00482.x

DUAN Jinyun ; WANG Juanjuan; ZHU Yuelong. (2014) ; Organizational Climate: A Review of Conceptualization, Theory and Prospects[J]. Advances in Psychological Science, 22(12) : 1964-1974. Retrieved from https://doi.org/10.3724/SP.J.1042.2014.01964

Daft, R.L. (1978) 'A Dual-Core Model of Organizational Innovation'. Academy of Management Review, 21, 193-210. Retrieved from https://doi.org/10.2307/255754

Drexler, J. A. (1977). Organizational climate : Its homogeneity within organizations. Journal of Applied Psychology, 62(1), 38-42. Retrieved from https://doi.org/10.1037/0021-9010.62.1.38

Ekvall, G. (1996) 'Organizational Climate for Creativity and Innovation'. European Journal of Work and Organizational Psychology, 5 (1), 105-23. Retrieved from https://doi.org/10.1080/13594329608414845

Fey, Carl \& Beamish, Paul. (2001). Organizational Climate Similarity and Performance : International Joint-Ventures in Russia. Organization Studies ORGAN STUD. 22. 853-882. 10.1177/0170840601225005. Retrieved from https://doi.org/10.1177/0170840601225005

Forehand, G. A., \& Gilmer, B. V. H (1964) ; "Environmental Variation in Studies of Organizational Behavior. Psychological Bulletin, 62, 361-382. Retrieved from https://doi.org/10.1037/h0045960

Ghavifekr, Simin; Pillai, Nova Sheila, (2016); The Relationship between School's Organizational Climate and Teacher's Job Satisfaction: Malaysian Experience. Asia Pacific Education Review, v17 n1 p87-106. Retrieved from https://doi.org/10.1007/s12564-015-9411-8

Glick, W. H. (1985). Conceptualizing and Measuring Organizational and Psychological Climate : Pitfalls in Multilevel Research. Academy of Management Review, 10, 601-616. Retrieved from https://doi.org/10.5465/amr.1985.4279045

Hannnes Zaher \& Jie Yang (2016) ; Organizational Climate for successful aging ; Front. Psychol., 04 July $2016 \quad$ |. Retrieved from https://doi.org/10.3389/fpsyg.2016.01007

I Putu Agus Suwastawa, I GDE Adnyana Sudibya, (2019) ; "The Effect of Organizational Climate and Compensation on Job Satisfaction and Employee Turnover Intention" : International Journal of Science and Research (IJSR), https://www.ijsr.net/search_index_results_paperid.php?id=1021903, Volume 8 Issue 2, 244 - 24. 
Isaksen, S. G., \& Ekvall, G. (2010). Managing for innovation : The two faces of tension in creative climates. Creativity and Innovation Management, 19(2), 73-88. Retrieved from https://doi.org/10.1111/j.1467-8691.2010.00558.x

James, L. R., \& Jones, A. P. (1974). Organizational climate : A review of theory and research. Psychological Bulletin, 81(12), 1096-1112. Retrieved from https://doi.org/10.1037/h0037511

Jan, Ms \& Khan, Mahmood. (2015). Morale of Teachers Working in Various Higher Secondary Schools of Kashmir Division-A Comparative Study of Science and Arts Teachers. Global Advanced Research Journal of Educational Research and Review. $4 . \quad 170-175 . \quad$ Retrieved from https://www.researchgate.net/profile/Mahmood-Khan-

23/publication/326841771_Morale_of_Teachers_Working_in_Various_High er_Secondary_Schools_of_Kashmir_Division-

A_Comparative_Study_of_Science_and_Arts_Teachers/links/5b688b68458 51546c9f68738/Morale-of-Teachers-Working-in-Various-HigherSecondary-Schools-of-Kashmir-Division-A-Comparative-Study-of-Scienceand-Arts-Teachers.pdf

Khan, Shah \& Sharma, Deepti. (2020). Organizational Climate: Review. 10.13140/RG.2.2.13111.34723.

Kossivi, B., Xu, M., \&Kalgora, B. (2016). Study on determining factors of employee retention. Open Journal of Social Sciences, 4(05), 261-268. Retrieved from https://doi.org/10.4236/jss.2016.45029

Koys, D. J., \& DeCotiis, T. A. (1991). Inductive measures of psychological climate. Human Relations, 44(3), $265285 . \quad$ Retrieved from https://doi.org/10.1177/001872679104400304

Kristof- Brown, A. L., Zimmerman, R. D., \& Johnson, E. C. (2005). Consequences of individuals 'fit at work : a meta- analysis of person-job, person-organization, person-group, and person-supervisor fit. Personnel psychology, 58(2), 281342. Retrieved from https://doi.org/10.1111/j.1744-6570.2005.00672.x

Kundu, Kaushik. (2007). Development of the conceptual framework of organizational climate. Vidyasagar University Journal of Commerce. 12.

Licciardello, O., Di Marco, G., \& Mauceri, M. (2013). Motivations and Perceived Organizational Climate Among Volunteers of Italian Red Cross. Procedia Social and Behavioral Sciences, 84, 584 - 588. doi: 10.1016/j.sbspro.2013.06.608. Retrieved from https://doi.org/10.1016/j.sbspro.2013.06.608

Likert, R. (1967). The human Organization. New York, McGraw- Hill.

Lumpkin GT and Dess GG (1996) Clarifying the entrepreneurial orientation construct and linking it to performance. Academy of Management Review 21(1) : 135-172 from https://doi.org/10.5465/amr.1996.9602161568

Madhukar, Dr Vikas \& Sharma, Sulabh. (2017). Organisational Climate : A Conceptual Perspective. International Journal of Management and Business. 7. Retrieved from https://d1wqtxts1xzle7.cloudfront.net/55807254/IJMRA-12034-withcover-pagev2.pdf?Expires=1643872075\&Signature=L9lRuyZEbv1Gx5Et6zL5Efnlh9Z WdKKcMuii 6QhYW6x-3CC3i3NcFdZ c cql - 
fSbcTTdUE6rv0Q1PhqlYLmKEl20595s-

R8ZNZ YDJydHg2bjPoqK4FyNOyc2h5Fk-unUE34livSjk7HqG5KgjsFoI-

1o330hIdMwB6X9QzCzmSHYq29C1ggUfnpleoNbf5MPeGRGD0ZnE-

ST6ym-1unVBH16h7X6iwfhQZvg2YiS3kakJ5wN4-

Quz7kFM CsyKbhFYziWrV32PJ5jDwJTgoFeIVwkABigM8rPKxMMNWA7D

8nr $\sim$ XJBw $\sim$ VCW $\sim$ mPSjaoB6du-eqD7P92HfYWsrDUAkg_\&Key-Pair-

Id=APKAJLOHF5GGSLRBV4ZA

Maja Rožman and Tjaša Štrukelj (2021) ; Organisational climate components and their impact on work engagement of employees in medium-sized organisations ; Economic Research-Ekonomska Istraživanja, volume 34, number, pages 775-806, doi 10.1080/1331677X.2020.1804967, URL : https://doi.org/10.1080/1331677X.2020.1804967https://doi.org/10.108 0/1331677X.2020.1804967. Retrieved from https://doi.org/10.1080/1331677X.2020.1804967

Mathew, J., \& Selvi, U. (2007). Importance of Organisational Climate in Contemporary Management. Ushus Journal of Business Management, 6(2), 61-74. Retrieved from https://doi.org/10.12725/ujbm.11.6

McWinner Yawman (2019) ; Organizational Climate and Job Satisfaction : A literature review ; International Journal of Current Research Vol. 12, Issue, 02, pp.10013-10018, DOI : https://doi.org/10.24941/ijcr.37858.02.2020, Available online at http://www.journalcra.com.

Meghan M. Biro (2017, 31 March) Secret Productivity Killer : Too Many Rules in the Workplace. Retrieved from https://talentculture.com/secret-productivitykiller-too-many-rules-in-the-workplace/

Miller D (1983) The correlates of entrepreneurship in three types of firms. Management Science 29(7) : 770-791. Retrieved from https://doi.org/10.1287/mnsc.29.7.770

Monika, M. and 2Kaliyamurthy, K. (2016) ; A detail review of organizational climate; International Journal of Developmental Research; Vol. 06, Issue, 07, pp.8625-8633, Available online at http://www.journalijdr.com.

O.E. Omole, C.O. Oyetunji-Alemede, H.F. Oladundoye (2017) ; Organizational Climate Review (2019) ; African Journal online, V. 27, Iss. 1. Retrieved from https://www.ajol.info/index.php/ifep/article/view/185696.

Obeng AF, Zhu Y, Azinga SA, Quansah PE (2021) ; Organizational Climate and Job Performance : Investigating the Mediating Role of Harmonious Work Passion and the Moderating Role of Leader-Member Exchange and Coaching. SAGE Open. doi :10.1177/21582440211008456. Retrieved from https://doi.org/10.1177/21582440211008456

P. Yukthamarani Permarupan ; Abdullah Al- Mamun ; Roselina Ahmad Saufi; Noor Raihani Binti Zainol (2013); Organizational Climate on Employees' Work Passion: A Review; Canadian Social Science. Vol. 9, No. 4, 2013, pp. 63-68. DOI : 10.3968/j.css.1923669720130904.2612. ISSN 1712-8056 ISSN 19236697[Online]. www.cscanada.net, www.cscanada.org.

Patnoe S. (1988) Lewin's Theory and Method. In : A Narrative History of Experimental Social Psychology. Recent Research in Psychology. Springer, New York, NY. Retrieved from https://doi.org/10.1007/978-1-4757-20129_3 
Pavle KOMENIĆ, Vanda BAZDAN, Besim AGUŠAJ, (2016) ; The Organizational Climate and Employee Turnover Intention in Dubrovnik Hotels ; RIThink, 2016, Vol. 5.

Powell BJ, Mettert KD, Dorsey CN, et al. (2021) ; Measures of organizational culture, organizational climate, and implementation climate in behavioral health: A systematic review. Implementation Research and Practice. doi :10.1177/26334895211018862. Retrieved from https://doi.org/10.1177/26334895211018862

Prange, Christiane \& Mayrhofer, Ulrike (2015). Alliances and Joint-Ventures. 10.1002/9781118785317.weom060007. Retrieved from https://doi.org/10.1002/9781118785317.weom060007

Rudd.D, Mills J.R (2020) ; Journal of Applied Business and Economics, Vol 22 (9).

Sambandam, Raja \& Chockalingam, Madhavi. (2019). Influence of Organizational Climate on Employee Performance in Manufacturing Industry. Volume-9. 146.

Sargunam, Silas \& Rathnamala, M.S. (2014). Manuscript title: Impact of Organizational Climate: A study on Anna university affiliated engineering colleges in Tamil Nadu. International Business Management. 8. 196-199. 10.3923/ibm.2014.196.199.

Schneider B, Ehrhart MG, Macey WH. (2012) Organizational climate and culture. Annu Rev Psychol. 2013 ;64 :361-88. doi : 10.1146/annurev-psych-113011143809. Epub. Jul 30. PMID : 22856467. Retrieved from https://doi.org/10.1146/annurev-psych-113011-143809

Schneider, B. (1975). Organizational climate: Individual preferences and organizational realities revisited. Journal of Applied Psychology, 60(4), 459465. Retrieved from https://doi.org/10.1037/h0076919

Schneider, B. (1985). Organizational behaviour. Annual Review of Psychology, 36 : 573-611. Retrieved from https://doi.org/10.1146/annurev.ps.36.020185.003041

Schneider, B. and Snyder, R.A. (1975) Some Relationship between Job Satisfaction and Organizational Climate. Journal of Applied Psychology, 60, 318-328. Retrieved from https://doi.org/10.1037/h0076756

Schneider, B., \& Bowen, D. E. (1984). New servicesdesign, development and implementation and the em-ployee. In W. R. George \& C. E. Marshall (Eds.) Developing new services (pp. 92-101). Chicago : Amer-ican Marketing Association

Sethibe T, Steyn R. (2018) ; The Mediating Effect of Organizational Climate on the Relationship between Leadership Styles and Their Components on Innovative Behaviour. Journal of Entrepreneurship and Innovation in Emerging Economies ;4(1) :22-32. doi :10.1177/2393957517747313 Retrieved from https: //doi.org/10.1177/2393957517747313

Sharma, M. (1969). A comparative study of organization climate of government secondary school and private secondary school of Churu district, Rajasthan. JournAl of EducAtionAl ReseArch And Extension, 5(3), 120- 126

Shreedevi Shintri, Dr. S R Bharamanaikar (2017) ; International Journal of Science and Technology Management, Vol. 6, Is. 03, website : ijstm.com, ISSN(Online) 2394-1537 ISSN(Print) 2394-1529. 
Skvarciany, Viktorija \& Iljins, Juris \& Gaile-Sarkane, Elina. (2015). Impact of Organizational Culture on Organizational Climate During the Process of Change. Procedia - Social and Behavioral Sciences. 213. 944-950. 10.1016/j.sbspro.2015.11.509. Retrieved from https://doi.org/10.1016/j.sbspro.2015.11.509

Skvarciany, Viktorija \& Iljins, Juris \& Gaile-Sarkane, Elina. (2015). Impact of Organizational Culture on Organizational Climate during the Process of Change.

Srivastav, A. K. (2009). Heterogeneity of Organisational Climate, Research and Practice in Human Resource Management, 17(2), 1-13.

Suresh Kumar (2011) ; An Overview of Organizational Climate in Bhakra Beas Management Board ; Journal of Social and Development Sciences Vol. 1, No. 4, pp. 138-143. Retrieved from https://doi.org/10.22610/jsds.v1i4.637

Syed Sadullah Hussainy, (2019) ; Effective Employees' Retention Strategies : Key to Manage Employees' turnover. (A Study of Omani Organizations) ; 2019 IJRAR June 2019, Volume 6, Issue 2 www.ijrar.org (E-ISSN 2348-1269, PISSN 2349-5138) V.7, P. https://www.frontiersin.org/article/10.3389/fpsyg.2016.01007, DOI=10.3389/fpsyg.2016.01007, ISSN=1664-1078

Yee Poh Li, Ananthalakshmi Mahadevan (2017) ; A study on the impact of Organizational Climate on employees Performance : International Journal of Accounting \& Business Management www.ftms.edu.my/journals/index.php/journals/ijabm Vol. 5 (No.1), ISSN : 2289-4519 DOI : 24924/ijabm/2017.04/v5.iss1/1.13.

Yström, Anna \& Aspenberg, Hedvig \& Kumlin, Annika. (2015). Exploring the creative climate in an open innovation arena : Identifying challenges and possibilities. European Journal of Innovation Management. 18. 70-85. 10.1108/EJIM-08-2013-0085. Retrieved from https://doi.org/10.1108/EJIM-08-2013-0085

Zacher Hannes, Yang Jie (2016) ; Organizational Climate for Successful Aging; Frontiers in Psychology from https://doi.org/10.3389/fpsyg.2016.01007 